\title{
Oriented T4 Bacteriophage Immobilization for Recognition of Escherichia coli in Capacitance Method
}

\author{
Danial Ashiani ${ }^{1}$, Amir Homayoun Keihan ${ }^{2}$, Jamal Rashidiani ${ }^{1}$, Fariba Dashtestani ${ }^{3}$, \\ Khadijeh Eskandari ${ }^{1, *}$ \\ ${ }^{1}$ Nanobiotechnology Research Center, Baqiyatallah University of Medical Sciences, Tehran, Iran \\ 2 Molecular Biology Research Center, Baqiyatallah University of Medical Sciences, Tehran, Iran \\ ${ }^{3}$ Institutes of Biochemistry \& Biophysics, University of Tehran \\ *E-mail: kheskandari@alumni.ut.ac.ir
}

doi: $10.20964 / 2016.12 .16$

Received: 23 July2016/ Accepted: 11 September 2016/ Published: 10 November 2016

One of the important aspects in biotechnology is the development of a rapid and selective approachfor the identification and quantization of Escherichia coli $(E$. coli) bacteria. In this research, we fabricated a novel Label-free electrochemical $E$. coli biosensor based on oriented immobilization of T4 biotinylated bacteriophage as recognition receptor of E. coli on streptavidin immobilized on polyanilin (PANI) glassy carbon (GC) modified electrode. Labeled PANI was synthesized by chemical method and characterized by Raman and cyclic voltammetry (CVs) and field emission scanning electron microscope (FESEM). The bacteriophage/PANI/GC electrodes were applied as indicator electrodes for capacitance determination of $E$. coli bacteria. By fabricating this biosensor, E. coli was sensed in a linearrange and detection limit of $10-98 \mathrm{~N} / \mathrm{mL}$ and $10 \mathrm{~N} / \mathrm{mL}$ ( $\mathrm{N}$ stands for number of E. coli) respectively. The proposed biosensor shows fast response time of $\sim 1 \mathrm{~s}$ and good selectivity over other bacteria. We successfully developed and implemented an E. coli biosensor based on oriented bacteriophage immobilization on PANI modified GC electrode. This biosensor is cost-effective, rapid, renewable and high selective for detection of E. coli bacteria. Also, this method can be extension to detection of other biological agents.

Keywords: E. coli, bacteriophageT4, capacitance, biosensor, PANI.

\section{FULL TEXT}

(C) 2016 The Authors.Published by ESG (www.electrochemsci.org). This article is an open access article distributed under the terms and conditions of the Creative Commons Attribution license (http://creativecommons.org/licenses/by/4.0/). 